\title{
PREGNANCY OUTCOMES IN WOMEN WITH GESTATIONAL DIABETES COMPARED WITH THE GENERAL OBSTETRIC POPULATION
}

\author{
By
}

\author{
Abdalla M. El-Shikh ${ }^{1 *}$, Mostafa H. Hegab ${ }^{1}$, Fahd A. Al-Omda ${ }^{1}$ and Wael \\ R. Hablas ${ }^{1}$ \\ ${ }^{1}$ Obstetrics and Gynecology Department, Faculty of Medicine, Al-Azhar University \\ *Corresponding Author: Abdalla Mohamed Ezeldin El-Shikh, \\ Mobile: 01002200274, E-mail: abdo4442000@ gmail.com
}

\begin{abstract}
Background: Gestational diabetes mellitus (GDM) is the most prevalent metabolic disorder during pregnancy. It is described as the vulnerability to impaired glucose tolerance of multiple severities, usually during pregnancy.

Objective: To compare pregnancy outcome in pregnant women with gestational diabetes mellitus and pregnant women in general population.

Patients and Methods: A prospective non-intervention observational study was conducted in Obstetrics and Gynecology Department, Faculty of Medicine, Al-Azhar University, Samanoud General Hospital and Private Clinics during the period from October 2017 to October 2020. This study included 200 primigravida singleton pregnant women between 24 weeks and 28 weeks of gestation divided into two equal groups: case group included pregnant women attended for their routine antenatal care and discovered to have gestational diabetes and control group included normal healthy pregnant women attended for their routine antenatal care.

Results: Fetal weight was significantly higher among study group than controls. Fetal complications in the form of Large for Gestational Age (LGA), premature, shoulder dystocia, hypoglycemia and hyperbilirubinemia were significantly higher among study group than controls. Neonatal Intensive Care Unit (NICU) admission was significantly higher among study group was (14\%) than controls (3\%).
\end{abstract}

Conclusion: Increased maternal and fetal morbidity is linked with maternity gestational diabetes. Early screening, diagnosis, closer monitoring, and intervention were also important to minimize short and longterm maternal and fetal adverse effects, in particular in populations that are high-risk.

Keywords: Gestational Diabetes, Pregnancy Outcomes, General Obstetric Population.

\section{INTRODUCTION}

Gestational diabetes mellitus (GDM) is the most prevalent metabolic disorder during pregnancy. It described as the vulnerability to the glucose of multiple severities, usually during pregnancy. It is usually diagnosed with an oral glucose tolerance test in the second trimester of pregnancy at 24 to 28 weeks of gestation
(Colberg et al., 2013). Numerous epidemiological research suggests that, based on the demographic surveyed and the diagnosis criteria, this condition affects between 1 and $18 \%$ of pregnancies. Its results are increasing gradually (Kaiser et al., 2013).

Maternal risks of gestational diabetes mellitus (GDM) have also been 
established as: having gestational diabetes mellite (GDM) history, diabetes family history, obesity, chronic urinary tract infections, treatment of miscarriage, unexplained neonatal mortality, macrosomal infants, late, pre-eclampsia and early maternal age (Khan et al., 2013). Patients with prior experience of diabetes mellitus (chronic/chronic kidney disease) and obesity medical problems (Al-Azemi et al., 2013).

In an effort to unite the gestational diabetes mellitus (GDM) criteria worldwide, the International Association of Diabetes and Maternity Research Groups (IADPSG) have adopted gestational diabetes mellitus (GDM) criteria. The IADPSG requirements require three samples: fasting, one hour, and two hours after $75 \mathrm{~g}$ glucose, where two specimens, namely fasting, and two hours, are required as a WHO criterion (Nallaperumal et al., 2013). Gestational diabetes mellitus (GDM) is a reversible disease and the risk associated with this is effectively minimized by women with a sufficient control of their glucose levels (Bhat et al., 2012).

Pregnancies affected by GDM bear a chance of adverse effects such as a caesarean section needed due to fetal macrosomia. Macrosomia is leading to the accelerated fetal growth of maternal hyperglycemia (Kamana et al., 2015). The prevalence of progression from GDM to abnormal glucose or type 2 diabetes varies greatly. The lifetime cumulative incidence of diabetes among women with GDM is about 60\% (Noctor and Dunne, 2015).

It is necessary to recognize pregnant women with GDM risk in the light of these associations in order to introduce preventive management such as lifestyle amendments (Webber et al., 2015).

In this research, we intended to compare pregnancy outcomes in pregnant women with gestational diabetes mellitus and pregnant women in general population.

\section{PATIENTS AND METHODS}

A prospective non-intervention observational study conducted in Obstetrics and Gynecology Department, Faculty of Medicine, Al-Azhar University, Samanoud general hospital and private clinics during the period from March 2017 to May 2020. This study included 200 singleton pregnant women between 24 weeks and 28 weeks of gestation divided into two groups:

- Case group (100 pregnant) included pregnant women attended for their routine antenatal care and discovered to have gestational diabetes.

\section{- Control group (100 pregnant) included normal healthy pregnant women attended for their routine antenatal care.}

\section{Ethical approval:}

The study was approved by the Ethics Board of Al-Azhar University and an informed written consent was taken from each participant in the study.

\section{Inclusion criteria:}

- Primi-gravida.

- Singleton pregnancies.

\section{Exclusion criteria:}

- Pre-existing diabetes and other endocrine diseases (e.g., 
hyperthyroidism, hypothyroidism and Cushing's syndrome).

- Multiple pregnancies.

- History of chronic hypertension, heart disease, hematological disease or renal disease.

- Taking corticosteroids.

- History of known fetal anomaly.

\section{Methods:}

All cases who met inclusion criteria had been subjected to the following:

- Full history taking: including personal, present, past, family, obstetric, contraceptive and menstrual history, gestational age is assessed by means of first day of last menstrual period (LMP).

- General examination and abdominal examination

- Investigations:

- Maternal investigations: (CBC, FBS, 2-hour postprandial sugar and Urine analysis).

- Fetal investigations: included obstetric ultrasound and CTG for fetal well-being.

Women had been screened for gestational diabetes using the 2-hour $75 \mathrm{~g}$ oral glucose tolerance test (OGTT). Diagnose gestational diabetes if the woman has either [15]:

- A fasting plasma glucose level of $5.6 \mathrm{mmol} / \mathrm{liter}(100.8 \mathrm{mg} / \mathrm{dl})$ or above or

- A 2-hour plasma glucose level of $7.8 \mathrm{mmol} / \mathrm{liter}(140.4 \mathrm{mg} / \mathrm{dl})$ or above
In all women with gestational diabetes, $\mathrm{HbA1c}$ levels were assessed at diagnosis to determine which women may have prior type 2 diabetes. People with gestational diabetes have been taught blood glucose self-monitoring, and women with rapid plasma glucose levels below $7 \mathrm{mmol} /$ liter $(126 \mathrm{mg} / \mathrm{dl})$ were given diagnosis for dietary changes and workouts. In women with gestational diabetes with rapid plasma glucose of $7.0 \mathrm{mmol} / 1 \quad(126 \mathrm{mg} / \mathrm{dl}) \quad$ or higher diagnoses, we proposed prompt insulin therapy and improvements in food and exercise. (National Institute for Health and Care Excellence. 2015).

\section{Statistical Analysis of Data:}

The collected data organized, tabulated and statistically analyzed using are statistical package for social sciences (SPSS) version 22 (SPSS Inc, Chicago, USA). For qualitative data, frequency and percent distributions were calculated. For quantitative data, mean, standard Deviation (SD), minimum and maximum was calculated. Statistical significance was defined as $\mathrm{P}$ value $<0.05$.

\section{The following tests were done:}

- Independent-samples t-test of significance was used when comparing between two means.

- Chi-square test for categorical variables, to compare between different groups.

- Mann-Whitney U test was used to compare age. 


\section{RESULTS}

There was no significant difference regard age or Gestational Age. Mean BMI was significantly higher among study group $(30.56 \pm 4.33)$ than control $(25.23 \pm 3.28) \quad(p=0.001)$ with significant higher percentage of obese among study group (47\%). Also, study group had higher family history of diabetes than controls $(\mathrm{p}<0.001)$ (Table 1).

Table (1): Basic demographic data distribution between groups at time of beginning of the study

\begin{tabular}{|c|c|c|c|c|c|}
\hline \multicolumn{3}{|c|}{$\begin{array}{ll}\text { Parameters } & \text { Groups } \\
\end{array}$} & $\begin{array}{c}\text { Study } \\
(\mathbf{N}=100)\end{array}$ & $\begin{array}{l}\text { Control } \\
(\mathbf{N}=\mathbf{1 0 0})\end{array}$ & $\mathbf{P}$ \\
\hline \multicolumn{3}{|l|}{ Age } & $32.25 \pm 9.91$ & $29.1 \pm 8.78$ & 0.113 \\
\hline \multicolumn{3}{|c|}{ Gestational Age } & $27.46 \pm 1.35$ & $30.4 \pm 1.32$ & $>0.05$ \\
\hline \multirow{7}{*}{$\begin{array}{l}\text { BMI } \\
\text { group }\end{array}$} & \multirow{2}{*}{ Average } & $\mathbf{N}$ & 13 & 66 & \multirow{6}{*}{$<0.001$} \\
\hline & & $\%$ & $13 \%$ & $66 \%$ & \\
\hline & \multirow{2}{*}{ Overweight } & $\mathbf{N}$ & 40 & 26 & \\
\hline & & $\%$ & $40 \%$ & $26 \%$ & \\
\hline & \multirow{2}{*}{ Obese } & $\mathbf{N}$ & 47 & 8 & \\
\hline & & $\%$ & $47 \%$ & $8 \%$ & \\
\hline & \multicolumn{2}{|c|}{ Mean \pm SD } & $30.56 \pm 4.33$ & $25.23 \pm 3.28$ & 0.001 \\
\hline \multirow{6}{*}{$\begin{array}{c}\text { Family } \\
\text { history of } \\
\text { diabetes }\end{array}$} & \multirow{2}{*}{-VE } & $\mathbf{N}$ & 23 & 73 & \multirow{6}{*}{$<0.001$} \\
\hline & & $\%$ & $23 \%$ & $73 \%$ & \\
\hline & \multirow{2}{*}{$1^{\mathrm{ST}}$ degree } & $\mathbf{N}$ & 56 & 17 & \\
\hline & & $\%$ & $56 \%$ & $17 \%$ & \\
\hline & \multirow{2}{*}{ Relative } & $\mathbf{N}$ & 21 & 10 & \\
\hline & & $\%$ & $21 \%$ & $10 \%$ & \\
\hline
\end{tabular}

BMI, body mass index (calculated as weight in kilograms divided by the square of height in meters); GDM, gestational diabetes mellitus; SD, standard deviation.

Regarding fasting blood glucose (FBG), 2 hours postprandial and HbA1c at diagnosis, there were significantly higher among study group than control group while at delivery, FBG and HbA1c were non significantly higher among study group than control group and 2 hours postprandial was significantly higher among study group than control group (Table 2).

Table (2): Marker distribution between groups at diagnosis and delivery

\begin{tabular}{|l|c|c|c|}
\hline Parameters & Study $(\mathbf{N}=100)$ & Control $(\mathbf{N}=100)$ & P \\
\hline At Diagnosis & $105.83 \pm 6.7$ & $75.66 \pm 6.64$ & $\mathbf{0 . 0 0 0}$ \\
\hline FBG & $166.66 \pm 7.39$ & $132.06 \pm 8.77$ & $\mathbf{0 . 0 0 0}$ \\
\hline 2 hours postprandial & $6.29 \pm 0.48$ & $5.36 \pm 0.35$ & $\mathbf{0 . 0 2 6}$ \\
\hline HbA1c & $91.15 \pm 5.3$ & $77.31 \pm 4.24$ & 0.182 \\
\hline At Delivery & $158.37 \pm 8.46$ & $126.84 \pm 6.27$ & $\mathbf{0 . 0 0 0}$ \\
\hline FBG & $6.08 \pm 1.35$ & $5.76 \pm 1.18$ & 0.105 \\
\hline 2 hours postprandial
\end{tabular}

FBG, fasting blood glucose. 
As regard to maternal complications, pregnancy induced hypertension, prolonged $\quad 2^{\text {nd }} \quad$ stage; postpartum hemorrhage and genital tract injury were higher in study group than control. There was statistically no significant difference between both groups as regard to prolonged $2^{\text {nd }}$ stage and postpartum hemorrhage (Table 3).

Table (3): Comparison between both groups as regard to maternal complications

\begin{tabular}{|c|c|c|c|c|}
\hline \multicolumn{2}{|c|}{ Groups } & $\begin{array}{c}\text { Study } \\
(\mathbf{N = 1 0 0})\end{array}$ & \multirow{2}{*}{$\begin{array}{c}\text { Control } \\
(\mathbf{N = 1 0 0})\end{array}$} & \multirow{2}{*}{$\mathbf{P}$} \\
\hline $\begin{array}{c}\text { Parameters } \\
\text { Pregnancy induced } \\
\text { hypertension }\end{array}$ & $\mathbf{N}$ & 2 & 1 & \multirow{2}{*}{$>0.05$} \\
\cline { 2 - 4 } $\begin{array}{c}\text { Prolonged 2nd } \\
\text { stage }\end{array}$ & $\mathbf{N}$ & $2 \%$ & $1 \%$ & \multirow{2}{*}{ NS $>0.05$} \\
\cline { 2 - 4 } $\begin{array}{c}\text { Postpartum } \\
\text { hemorrhage }\end{array}$ & $\mathbf{N}$ & 4 & 2 & \multirow{2}{*}{ NS $>0.05$} \\
\cline { 2 - 4 } $\begin{array}{c}\text { Genital tract } \\
\text { injury }\end{array}$ & $\mathbf{N}$ & $1 \%$ & 0 & \multirow{2}{*}{$>0.05$} \\
\cline { 2 - 4 } & $\mathbf{\%}$ & $3 \%$ & $2 \%$ & \\
\hline
\end{tabular}

There was significant difference between groups as regard to mode of delivery $(\mathrm{p}=0.001)$. CS rate was higher among gestational diabetes group (49\%) (Table 4).

Table (4): Obstetric characters distribution between groups

\begin{tabular}{|c|c|c|c|c|c|}
\hline Parameters & & & $\begin{array}{c}\text { Study } \\
(\mathbf{N}=100)\end{array}$ & $\begin{array}{l}\text { Control } \\
(\mathrm{N}=100)\end{array}$ & $\mathbf{P}$ \\
\hline \multirow{4}{*}{ Mode of delivery } & \multirow{2}{*}{ CS } & $\mathbf{N}$ & 49 & 30 & \multirow{4}{*}{0.006} \\
\hline & & $\%$ & $49.0 \%$ & $30 \%$ & \\
\hline & \multirow{2}{*}{ Vaginal } & $\mathbf{N}$ & 51 & 70 & \\
\hline & & $\%$ & $51.0 \%$ & $70 \%$ & \\
\hline \multirow{4}{*}{$\begin{array}{l}\text { Intra operative } \\
\text { blood transfusion }\end{array}$} & \multirow{2}{*}{$+\mathrm{VE}$} & $\mathbf{N}$ & 2 & 1 & \multirow{4}{*}{$>0.05$} \\
\hline & & $\%$ & $2 \%$ & $1 \%$ & \\
\hline & \multirow{2}{*}{$-V E$} & $\mathbf{N}$ & 98 & 99 & \\
\hline & & $\%$ & $98 \%$ & $99 \%$ & \\
\hline
\end{tabular}

Regarding fetal outcome, fetal weight was significantly higher among study group (3850.0 \pm 513.7$)$ than controls $(3396.6 \pm 334) \quad(\mathrm{p}<0.001) . \quad$ Fetal complications in the form of LGA, premature, shoulder dystocia, hypoglycemia and hyperbilirubinemia were significantly higher among study group than controls. NICU admission was significantly higher among study group $(14 \%)$ than controls $(3 \%) \quad(\mathrm{p}=0.006)$ (Table 5). 
ABDALLA M. EL-SHIKH et al.,

Table (5): Fetal outcome distribution between groups

\begin{tabular}{|c|c|c|c|c|c|}
\hline \multicolumn{3}{|c|}{$\begin{array}{ll}\text { Parameters } & \text { Groups } \\
\end{array}$} & $\begin{array}{c}\text { Study } \\
(\mathbf{N}=100)\end{array}$ & $\begin{array}{l}\text { Control } \\
(\mathrm{N}=100)\end{array}$ & $\mathbf{P}$ \\
\hline Fetal weight & \multicolumn{2}{|c|}{ Mean \pm SD } & $3850.0 \pm 513.7$ & $3396.6 \pm 334.7$ & $<0.001$ \\
\hline \multirow{4}{*}{ Fetal sex } & \multirow{2}{*}{ Male } & $\mathbf{N}$ & 44 & 47 & \multirow{4}{*}{$>0.05$} \\
\hline & & $\%$ & $44 \%$ & $47 \%$ & \\
\hline & \multirow{2}{*}{ Female } & $\mathbf{N}$ & 56 & 53 & \\
\hline & & $\%$ & $56 \%$ & $53 \%$ & \\
\hline \multirow{14}{*}{$\begin{array}{c}\text { Fetal } \\
\text { complication }\end{array}$} & \multirow{2}{*}{ No } & $\mathbf{N}$ & 57 & 97 & \multirow{2}{*}{$<0.001$} \\
\hline & & $\%$ & $57 \%$ & $97 \%$ & \\
\hline & \multirow{2}{*}{ LGA } & $\mathbf{N}$ & 33 & 4 & \multirow{2}{*}{$<\mathbf{0 . 0 0 1}$} \\
\hline & & $\%$ & $33 \%$ & $4 \%$ & \\
\hline & \multirow{2}{*}{ Premature } & $\mathbf{N}$ & 3 & 1 & \multirow{2}{*}{$>0.05$} \\
\hline & & $\%$ & $3 \%$ & $1 \%$ & \\
\hline & \multirow{2}{*}{ Neonatal death } & $\mathbf{N}$ & 1 & 0 & \multirow{2}{*}{$>0.05$} \\
\hline & & $\%$ & $1 \%$ & $0 \%$ & \\
\hline & \multirow{2}{*}{$\begin{array}{l}\text { Shoulder } \\
\text { dystocia }\end{array}$} & $\mathbf{N}$ & 4 & 0 & \multirow{2}{*}{0.02} \\
\hline & & $\%$ & $4 \%$ & $0 \%$ & \\
\hline & \multirow{2}{*}{ Hypoglycemia } & $\mathbf{N}$ & 3 & 0 & \multirow{2}{*}{0.04} \\
\hline & & $\%$ & $3 \%$ & $0 \%$ & \\
\hline & \multirow{2}{*}{$\begin{array}{c}\text { Hyperbilirubine } \\
\text { mia }\end{array}$} & $\mathbf{N}$ & 11 & 2 & \multirow{2}{*}{$<\mathbf{0 . 0 1}$} \\
\hline & & $\%$ & $11 \%$ & $2 \%$ & \\
\hline \multirow{4}{*}{$\begin{array}{c}\text { NICU } \\
\text { admission }\end{array}$} & \multirow{2}{*}{ Yes } & $\mathbf{N}$ & 14 & 3 & \multirow{4}{*}{$<\mathbf{0 . 0 0 6}$} \\
\hline & & $\%$ & $14 \%$ & $3 \%$ & \\
\hline & \multirow{2}{*}{ No } & $\mathbf{N}$ & 86 & 97 & \\
\hline & & $\%$ & $86 \%$ & $97 \%$ & \\
\hline
\end{tabular}

LGA, large for gestational age; NICU, neonatal intensive care unit.

\section{DISCUSSION}

The elevated risk of pregnancy induced hypertension $(\mathrm{PIH})$ with relative risk varies from 1.4 to 4.15 . It has been correlated with gestational diabetes mellitus, although some reports indicate that the association between PIH and GDM was not well-understood. This further raised the cesarean delivery rate by up to $57,4 \%$ and has a higher influence in obese and/or prior cesarean section history cases. GDM has been linked with a risk of labor-induction of 33-38 percent, premature membrane breakdown, antepartum hemorrhage (APH) and postpartum hemorrhage (PPH) (Kari et al., 2017).
The present study showed that Fasting Blood Glucose (FBG), 2 hours postprandial and Hemoglobin A1c (HbA1c) were significantly higher among study group than control group. At delivery, FBG and HbA1c were non significantly higher among study group than control group, while 2 hours postprandial was significantly higher among study group than control group.

Our findings were confirmed by a study conducted by Muche and Others (2019) who suggested that plasma glucose levels were considerably different in women with GDM and standard glucose level in three oral glucose tolerance tests. Capula et al. (2013) found that the GDM treatment was effective in a wide decline 
of the HbA1c distribution with regard to HbA1c during OGTT time.

The present research has shown that hypertension, extended 2nd stage, postpartum hemorrhage and genital tract injury in the study are more important than control for maternal complications. The disparity in terms of long 2nd stage and postpartum hemorrhages were not statistically important.

The influence of pregnancy-induced hypertension (PIH), hypothyroidism and polyhydramnios in diabetic pregnancies were further observed in the study of Saxena et al. (2013). But there was no substantial difference between both classes with respect to pre-eclampsia in the analysis of Gracelyn \& Saranya (2016) and Rezaie et al., (2016).

The study of Muche et al. (2019) had at least one type of adverse maternal outcome. The proportion of adverse maternal outcome among mothers with and without GDM was $52.9 \%$ and $29.5 \%$, respectively. The overall incidence of $\mathrm{PIH}$ was $5.3 \%$, induction of labor was $13.5 \%$, PROM was 9.9\%, APH (Antepartum hemorrhage) was $7.5 \%$, and $\mathrm{PPH}$ was $4.9 \%$. The incidence of $\mathrm{PIH}$, induction of labor, PROM, APH, and PPH (Postpartum hemorrhage) was higher among women with GDM compared to those with nonGDM. It might be because GDM has a negative effect on placenta previa and abruption placentae leading to APH.

In the study in our hands, there was significant difference between groups as regard to mode of delivery. Cesarean section (CS) rate was higher among gestational diabetes group (49\%). Our findings were compatible with the research of Saxena et al. (2011) who observed that the delivery rate of caesareans was $71.4 \%$ to avoid potential shoulder dystocia, birth traumas and so on. The strategy is to take a cesarean option decision after an assessment of fetopelvic disproportion. The loss of work, failure to stimulate and irregular presentations are other explanations of cesarean delivery. In the research population there was minimal overall birth weight and fetopelvic disproportion, surgical and non-progressive delivery were not observed, likely because there were minimal samples and strict pregnancy range criteria.

The present study showed that fetal weight was significantly higher among study group than controls. Fetal complications LGA, premature, shoulder dystocia, hypoglycemia and hyperbilirubinemia were significantly higher among study group than controls. NICU admission was significantly higher among study group (14\%) than controls (3\%) which agree with a study of slagjana et al. (2020) that NICU admission in between pregnant women with GDM was significantly higher (about 12\%) than in normoglycemic pregnant women.

Our results were supported by Rezaie and Others (2016) who found that the difference in macrosomy between the two groups was statistically significant. Macrosomal disorder, contributing to shoulder dystocia and brachial plexus trauma, and high cesarean section rates due to lack of progress at labor, was one of the most common complication of gestational diabetes.

Gracelyn and Saranya (2016) revealed that macrosomic baby with a weight of $>$ $4 \mathrm{~kg}$ among pregnant women was $8.6 \%$. 
ABDALLA M. EL-SHIKH et al.,

In the GDM pregnant, 42.37 percent were delivering macrosomic baby compared to 4.08 percent of non GDM, However, they considered GDM and previous macrosomia to be unfavorable.

Saxena et al. (2011) recorded that the average birth weight for diabetic maternal neonates was $3.1 \pm 0.9 \mathrm{~kg}$ and for control groups was $2.7 \pm 0.5 \mathrm{~kg}$. Biochemical and metabolic investigations have shown that neonates from diabetic mothers had slightly high hypocalcemia, hyperbilirubinemia and polycythemia. Congenital abnormalities have been significantly elevated even in neonates with diabetes women and have been seen in non-diabetic neonates. Several anomalies were found, including palate splinters, foot drop $(n=1)$, pericardial splash, and anencephaly meningocele.

\section{CONCLUSION}

Increased maternal and fetal morbidity was linked with maternity gestational diabetes. Early screening, diagnosis, closer monitoring, and intervention were also important to minimize short and longterm maternal and fetal adverse effects, in particular in populations that were highrisk.

\section{REFERENCES}

1. Al-Azemi N, Diejomaoh MF, Angelaki $\mathbf{E}$ and Mohammed AT (2013): Clinical presentation and management of diabetes mellitus in pregnancy. Int J Women's Health 6: 1-10.

2. Bhat M, Ramesha KN, Sarma SP, Menon S and Ganesh Kumar S (2012): Outcome of gestational diabetes mellitus from tertiary referral center in South India: across-control study. J Obstet Gynaecol India, 62 (6): 644649.
3. Capula C, Chiefari E, Vero A, Arcidiacono B, Iiritano S, Puccio L, Pullano V, Foti DP, Brunetti A and Vero R (2013): Gestational diabetes mellitus: screening and outcomes in southern Italian pregnant women. International Scholarly Research Notices, 239.

4. Colberg SR, Castorino K and Jovanovic L (2013): Prescribing physical activity to prevent and manage gestational diabetes. World J Diabetes, 4 (6): 256-262.

5. Gracelyn LJ and Saranya N (2016): Prevalence of gestational diabetes mellitus in antenatal women and its associated risk factors. Int J Reprod Contracept Obstet Gynecol, 5(2):285-91.

6. Kaiser B, Razurel C and Jeannot E (2013): Impact of health beliefs, social support and self-efficacy on physical activity and dietary habits during the post-partum period after gestational diabetes mellitus: study protocol. BMC Pregnancy Childbirth 13 (1): 133.

7. Kamana Kc, Sumisti Shakya and Hua Zhang (2015): Gestational diabetes mellitus and macrosomia: Ann Nutr Metab., 66(suppl 2):14-20.

8. Kari A, Sahhaf $F$ and Abbasalizadeh $F$ (2017): Maternal, fetal and neonatal outcomes in mothers with diabetes mellitus or gestational diabetes that complicated with preterm premature rupture of the membrane (PPROM). Int J Womens Health Reprod Sci, 5(1):66-71.

9. Khan R, Ali K and Khan Z (2013): Maternal and fetal outcome of gestational diabetes mellitus. Gomal J Med Sci., 11: 88- 91.

10. Muche AA, Olayemi OO and Gete YK (2019): Prevalence of gestational diabetes mellitus and associated factors among women attending antenatal care at Gondar town public health facilities, Northwest Ethiopia. BMC Pregnancy and Childbirth, (1):334-340.

11. Nallaperumal $S$, Bhavadharini B, Mahalakshmi MM, Maheswari K, Jalaja R, Moses A, Anjana RM, Deepa M, Ranjani HM and Mohan V (2013): Comparison of the world health organization and the international association of diabetes and 
pregnancy study groups criteria in diagnosing gestational diabetes mellitus in South Indians. Indian J Endocrinol Metab., 17 (5): 906-909.

12. Noctor E and Dunne FP (2015): Type 2 diabetes after gestational diabetes: The influence of changing diagnostic criteria, World J Diabetes., 6(2): 234-244.

13. Rezaie M, Azimi M, Rahimi $\mathbf{E}$ and Vakili FZ (2016): Pregnancy outcomes in pregnant women with previous history of gestational diabetes. International Journal of Medical Research \& Health Sciences, 5(11):223-8.

14. Saxena P, Tyagi S, Prakash A, Nigam A and Trivedi SS (2011): Pregnancy outcome of women with gestational diabetes in a tertiary level hospital of north India. Indian Journal of Community Medicine: Official Publication of Indian Association of Preventive \& Social Medicine. 36(2):120-123.
15. Slagjana Simeonova K, Valentina Velkoska N, Igor S, Aleksandra Atanasova $B$ and Irena $T$ (2020): Perinatal Outcome in Gestational Diabetes Millets Vs Normoglycemic Women. Biomed J Sci \& Tech Res., 26(2): 19882-88.

16. Vanlalhruaii, Ranabir S, Prasad L, Singh NN and Singh TP (2013): Prevalence of gestational diabetes mellitus and its correlation with blood pressure in Manip. Indian J Endocrinol Metab., 17 (6): 957-61.

17. Webber J, Charlton $M$ and Johns N (2015): Diabetes in pregnancy: Management of diabetes and its complications from preconception to the postnatal period (NG3). British Journal of Diabetes \& Vascular Disease., 15(3): 107-110. 
مقارنة ناتج الحمل في السيدات الحو امل المصابات بسكري

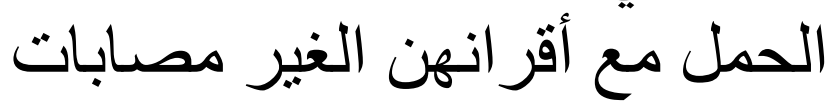

عبد الله محمد الثيخ1، مصطفى حسين محمد حجاب1، فهذ عبدالعال العمدة1، وائل

$$
\text { رفعت حبلص } 1
$$

1قسم أمراض النساء والتوليد، كلية الطب، جامعة الأزهر

البريد الاكتروني: abdo4442000@gmail.com، الموبيل:01002200274

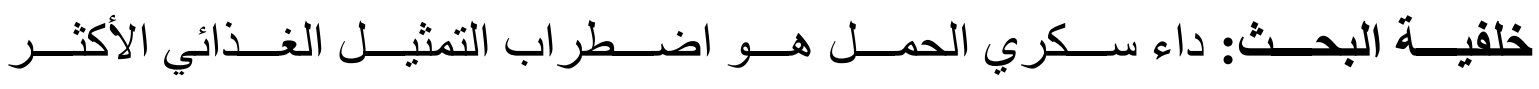

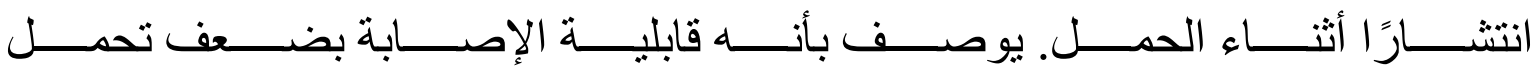
الجلوكوز متعدد الثدة، ويظهر عادة أثناء الحمل.

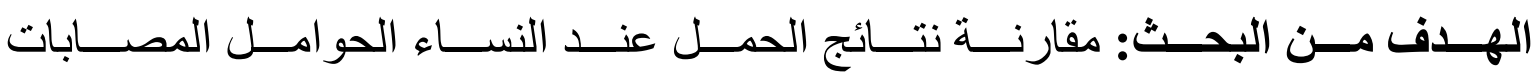
بداء سكري الحمل و النساء الحوامل في عموم السكان.

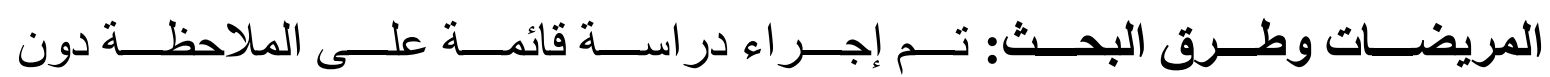

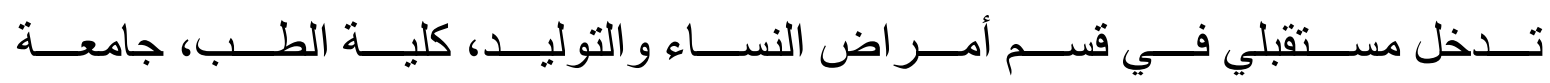

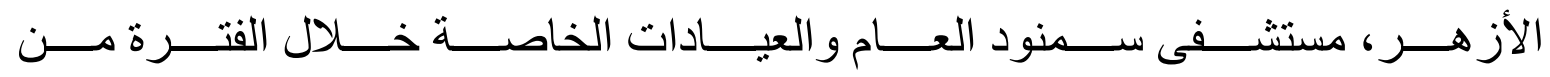

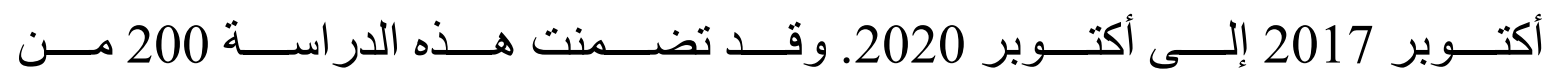

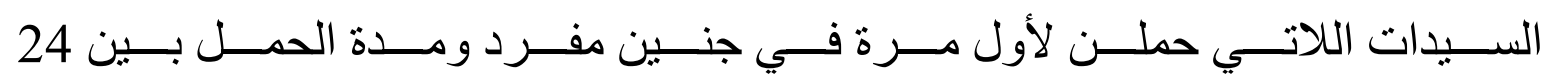

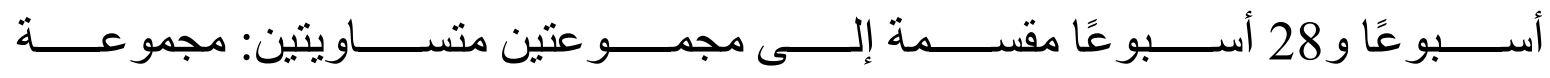

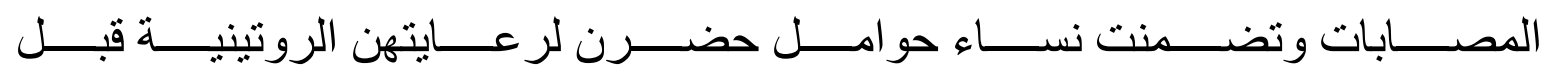

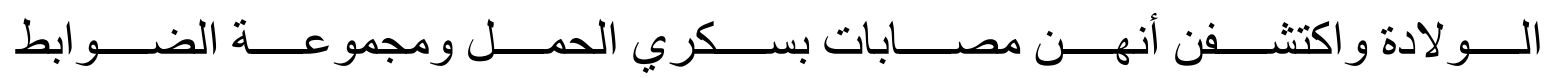

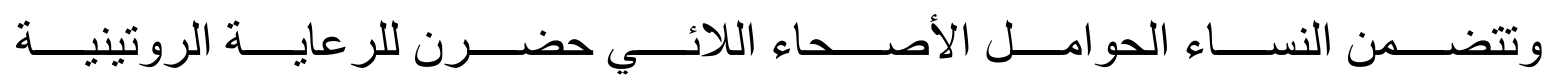

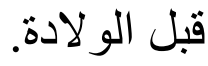

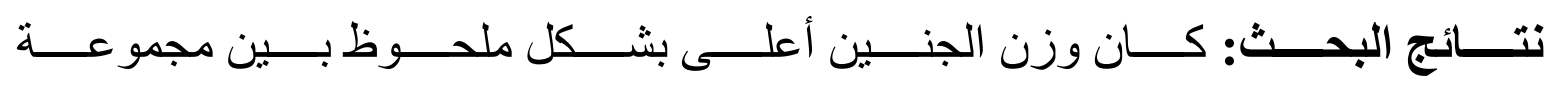

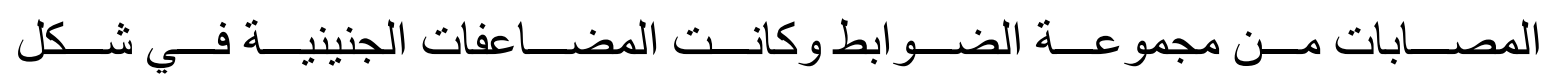




\section{PREGNANCY OUTCOMES IN WOMEN WITH GESTATIONAL...}

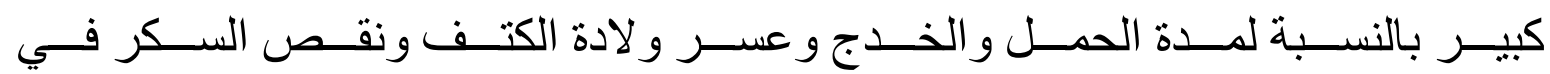

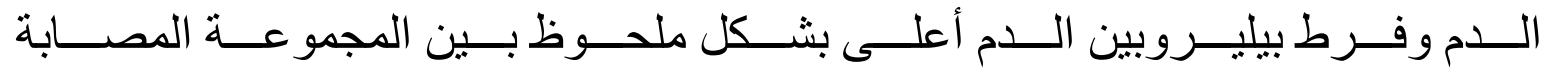

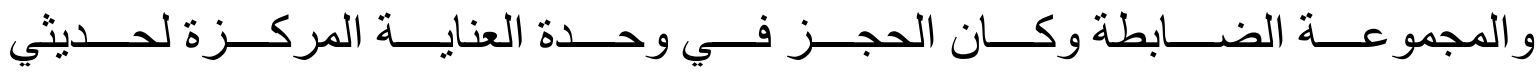

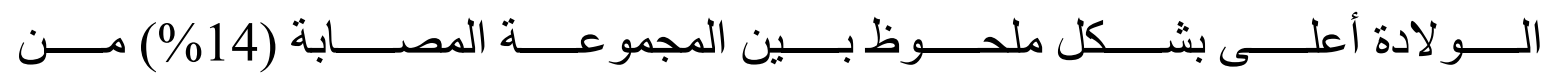
المجمو عة الضنابطة (33\%).

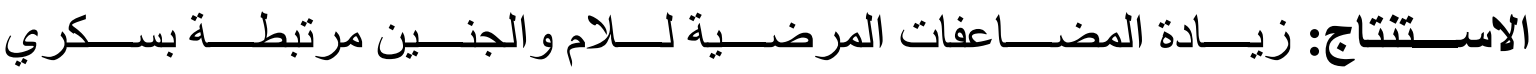

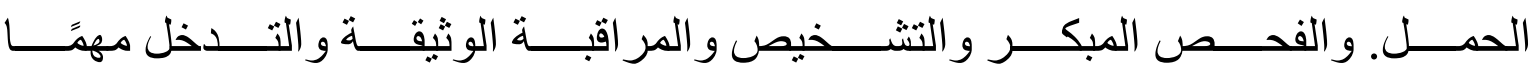

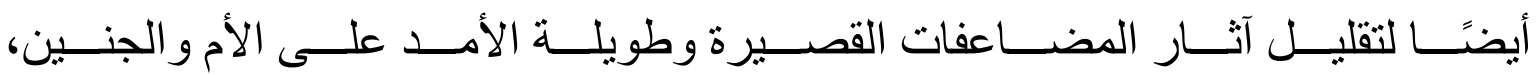
لا سيما في الفئات السكانية الأكثر عرضة للإصابة بسكري الحمل. الكلمات الدالة: سكري الحمل، نتائج الحمل، الحوامل من السكان. 